\title{
Avaliação do potencial alelopático, atividade antimicrobiana e antioxidante dos extratos orgânicos das folhas de Pyrostegia venusta (Ker Gawl.) Miers (Bignoniaceae)
}

\author{
SILVA, P.B. ${ }^{1}$; MEDEIROS, A.C.M. ${ }^{2}$; DUARTE, M.C.T. ${ }^{2}$ RUIZ, A.L.T.G. ${ }^{2}$; KOLB, R. M. ${ }^{1}$; FREI, F. ${ }^{1}$; SANTOS, C. ${ }^{\text {* }}$ \\ ${ }^{1}$ Faculdade de Ciências e Letras da Universidade Estadual Paulista/UNESP, Departamento de Ciências Biológicas, \\ Avenida Dom Antonio, 2100, Parque Universitário, CEP: 19806-900, Assis-Brasil *csantos@assis.unesp.br \\ ${ }^{2}$ Universidade Estadual de Campinas, Centro Pluridisciplinar de Pesquisas Químicas, Biológicas e Agrícolas - \\ CPQBA/UNICAMP, Caixa Postal 6171, CEP: 13081-970, Campinas-Brasil
}

\begin{abstract}
RESUMO: Este trabalho apresenta os resultados de atividade alelopática, antimicrobiana e antioxidante dos extratos orgânicos (hexano, acetato de etila e metanol) das folhas de Pyrostegia venusta (Ker Gawl.) Miers (Bignoniaceae). Para alelopatia, foi estudado o desenvolvimento de Cucumis sativus (pepino), sendo avaliados o comprimento da raiz principal, o número de raízes secundárias e o comprimento do hipocótilo. Os dois primeiros parâmetros foram afetados por todos os três extratos testados enquanto o comprimento do hipocótilo só não foi afetado pelo extrato acetato de etila. Quanto à atividade antimicrobiana, avaliada pelo ensaio de $\mathrm{CIM}$, o extrato hexânico apresentou inibição moderada frente ao Staphylococcus aureus $\left(0,9 \mathrm{mg} \mathrm{mL}^{-1}\right)$ e forte ao Enterococcus hirae $\left(0,5 \mathrm{mg} \mathrm{mL}^{-1}\right)$. $\mathrm{O}$ extrato acetato de etila apresentou forte atividade frente Candida albicans $\left(0,3 \mathrm{mg} \mathrm{mL}^{-1}\right)$ enquanto o extrato metanólico não mostrou-se ativo para os microrganismos testados. Por outro lado, o extrato metanólico apresentou a maior capacidade de seqüestrar radicais livres (Concentração Efetiva $50 \%-\mathrm{CE}_{50}=102,0 \pm 56,9 \mathrm{mg} \mathrm{mL}^{-1}$, com TCE TC $_{50}$ $=30 \mathrm{~min}$ ) no ensaio com DPPH (2,2-difenil-1-picril-hidrazila) e o maior teor de compostos fenólicos $(116,2 \pm 83,0 \mathrm{mg}$ ácido gálico $\mathrm{g}$ amostra-1 $)$, avaliado pelo ensaio de Folin-Ciocalteau.
\end{abstract}

Palavras-chave: Pyrostegia venusta, atividades alelopática, antimicrobiana, antioxidante

\begin{abstract}
Evaluation of allelopathic potential, antimicrobial and antioxidant activities of Pyrostegia venusta (Ker Gawl.) Miers (Bignoniaceae) leaf organic extracts. This paper presents the results of allelopathic, antimicrobial and antioxidant activities of organic extracts (hexane, ethyl acetate and methanol) from the leaves of Pyrostegia venusta (Ker Gawl.) Miers (Bignoniaceae). Allelopathic activity was assessed based on Cucumis sativus (cucumber) development for the parameters main root length, number of secondary roots and hypocotyl length. All tested extracts affected the first two parameters, while the hypocotyl length was not affected only by the ethyl acetate extract. For antimicrobial activity, assessed by MIC assay, hexane extract showed moderate inhibition for Staphylococcus aureus $\left(0.9 \mathrm{mg} \mathrm{mL}^{-1}\right)$ and strong inhibition for Enterococcus hirae $\left(0.5 \mathrm{mg} \mathrm{mL}^{-1}\right)$. Ethyl acetate extract showed strong activity against Candida albicans $\left(0.3 \mathrm{mg} \mathrm{mL}^{-1}\right)$, whereas methanolic extract was not active against the tested microorganisms. On the other hand, methanol extract showed the most promising radical scavenging capacity (Effective Concentration $50 \%-\mathrm{EC}_{50}=102.0 \pm 56.9 \mathrm{mg} \mathrm{mL}^{-1}$, with $\mathrm{TEC}_{50}=30$ $\mathrm{min}$ ) in DPPH assay (2,2-diphenyl-1-picryl-hidrazil) and the highest level of phenolic compounds (116.2 $\pm 83.0 \mathrm{mg}$ acid garlic $\mathrm{g}$ sample $\left.{ }^{-1}\right)$, as indicated by Folin-Ciocalteau assay.
\end{abstract}

Key words: Pyrostegia venusta, allelopathic, antimicrobial, antioxidant activities

\section{INTRODUÇÃO}

A espécie Pyrostegia venusta (Ker Gawl.) Miers (Bignoniaceae), conhecida popularmente por flor ou cipó-de-São-João, é uma trepadeira lenhosa, de folhas opostas, que possuem gavinhas trifurcadas com finos acúleos no ápice. As flores são vistosas e de cor laranja-avermelhadas. Com ampla distribuição

Recebido para publicação em 17/03/2009

Aceito para publicação em 24/03/2011

Rev. Bras. PI. Med., Botucatu, v.13, n.4, p.447-455, 2011. 
nacional, as folhas e flores são empregadas na medicina popular (Maroni et al., 2006), sendo que os extratos alcoólicos de flores e folhas são utilizados como remédio para tratar vitiligo (Ferreira et al., 2000). Recentemente, outras potencialidades biológicas foram relatadas a partir dos extratos das flores, como os estudos na melhora do sintoma da gripe, quando submetido aos extratos hidroetanólicos (Veloso et al., 2010) ou ainda a baixa genotoxicidade dos extratos etanólicos avaliados pelo teste de micronúcleo e o de aberração cromossômica, em ratos (Magalhães et al., 2010).

$\mathrm{Na}$ avaliação de quarenta espécies de Bignoniaceae, revelou-se que na $P$. venusta havia a presença de componentes fenólicos livres e grupos siringila (Satyavathi et al., 1984). A partir do extrato $\mathrm{MeOH}: \mathrm{H}_{2} \mathrm{O} 70 \%$ das folhas foi feito quantificação do teor de fenóis e flavonóides (Santos \& Blatt, 1998). No extrato etanólico das raízes foram identificados $\beta$ -

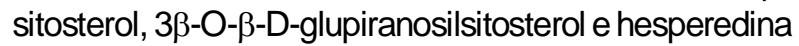
(Ferreira et al., 2000). A partir das flores foram isolados hentriacontano, 7-O- $\beta$-D-glicopiranosilacacetina, mesoinositol e também $\beta$-sitosterol (Dubey \& Misra, 1976). Nas plantas, as principais propriedades dos compostos fenólicos são a defesa contra a herbivoria, inibição da germinação de sementes, crescimento de fungos e alelopatia.

A alelopatia é usualmente definida como qualquer processo envolvendo metabólitos secundários produzidos por plantas e/ou microrganismos que, uma vez liberados no ambiente, influenciam o desenvolvimento de sistemas biológicos. Há imensa variedade de compostos com este tipo de atividade, como os ácidos orgânicos, naftoquinonas, antraquinonas, quinonas, fenóis, flavonóides e taninos (Carmo et al., 2007). Devido à variedade de atuação destes compostos, os aleloquímicos são considerados como recurso para o desenvolvimento de herbicidas naturais ou de estimulantes para o crescimento de algumas plantas (Bagchi et al., 1997). Para avaliação da ação dos aleloquímicos são realizados bioensaios com sementes sensíveis; as mais utilizadas como indicadores de alelopatia são Lactuca sativa L. (alface), Lycopersicon esculentum Miller (tomate) e Cucumis sativus L. (pepino), por serem de fácil aquisição e manuseio (Alves et al., 2004).

A busca por novos agentes antimicrobianos, para aplicação em produtos farmacêuticos e cosméticos, faz-se cada vez mais necessária, devido ao surgimento de microrganismos resistentes aos antibióticos em uso clínico, e aos microrganismos oportunistas que levam a infecções fatais. Desta forma, compostos provenientes de extratos de plantas podem contribuir para o desenvolvimento de antibióticos mais eficazes e menos tóxicos, na corrida contra a resistência e o surgimento de microrganismos patogênicos (Ostrosky et al., 2008). Em recente revisão, na família Bignoniaceae, destaca-se Clytostoma callistegioides (Cham.) Bur. (cipó-ouro) e Jacarandra micrantha (Cham.) plantas com indicativo popular de uso medicinal e que apresentaram atividade antiestafilócica (Wiest et al., 2009).

Por outro lado, existem cada vez mais evidências de que os radicais livres podem induzir danos oxidativos em biomoléculas e podem estar relacionados com o envelhecimento e a gênese de várias doenças, como câncer, diabetes, artrite, dentre outras (Degaspari \& Waszczynskyj, 2004). Neste contexto, muitas pesquisas têm demonstrado que compostos fenólicos oriundos de plantas, como os encontrados em P. venusta (Blatt et al., 1998; Santos \& Blatt, 1998; Ferreira et al., 2000), possuem grande potencial antioxidante (Sousa et al., 2007), por capturarem diretamente espécies reativas ou os intermediários reativos de uma série de reações junto com as enzimas antioxidantes (Andrade et al., 2007).

Baseado nas informações etnofarmacológicas da $P$. venusta este trabalho teve como objetivo avaliar o potencial alelopático, antimicrobiano e antioxidante de extratos de diferentes polaridades obtidos a partir das folhas de $P$. venusta.

\section{MATERIALE MÉTODO}

\section{Material Vegetal}

A coleta de folhas de $P$. venusta foi realizada a partir de vários indivíduos em estado vegetativo, nos arredores do campus da FCL/Assis-UNESP (2232'20"S e 5022'60"W) e a exsicata (SPSF 40.207) foi depositada no Herbário do Instituto Florestal "Don Bento Pickel", São Paulo, SP.

Após a coleta, o material foi seco em estufa a $60^{\circ} \mathrm{C}$ por dois dias. Em seguida, as folhas foram trituradas em processador doméstico e armazenadas em geladeira até uso posterior.

\section{Preparação dos extratos}

Inicialmente foi usado hexano, na proporção de $50 \mathrm{~g}$ do material vegetal $500 \mathrm{~mL}^{-1}$ do solvente, mantendo-se sob agitação magnética por duas horas. Em seguida, a solução foi filtrada e o resíduo reextraído por mais duas vezes, seguindo o mesmo processo. Os filtrados, agrupados e evaporados, resultaram no extrato hexânico (EHPV), com rendimento de 2,96\%. O resíduo vegetal foi então extraído três vezes com acetato de etila usando a mesma proporção acima fornecendo o extrato acetato de etila (EAPV) com rendimento de 2,88\%. Finalmente, o resíduo vegetal, resultante da extração com o acetato de etila, foi extraído com metanol (EMPV), com rendimento de $23,75 \%$.

\section{Avaliação do pH dos extratos}

$\mathrm{O} \mathrm{pH}$ foi avaliado, com pHmetro Tecnal

Rev. Bras. PI. Med., Botucatu, v.13, n.4, p.447-455, 2011. 
(modelo TEC-2), nos extratos orgânicos ressuspendidos em água (5 $\left.\mathrm{mg} \mathrm{mL}^{-1}\right)$.

\section{Bioensaio de Alelopatia}

O bioensaio foi realizado em placas de Petri (14 cm de diâmetro), previamente desinfetadas com hipoclorito de sódio $2 \%$ por 30 minutos, lavadas com água destilada e etanol 70\%; e, por último, secas em estufa a temperatura de $105^{\circ} \mathrm{C}$ por duas horas.

As sementes de pepino (variedade comercial Pepino Verde Comprido, ISLA sementes) foram colocadas em solução $2 \%$ de hipoclorito de sódio por dois minutos. Após este tempo, as sementes foram lavadas com água destilada para retirar todo resíduo do hipoclorito, estando prontas para a semeadura. As placas foram forradas com duas folhas de papel de filtro, umedecidas com solução $(10 \mathrm{~mL})$ do extrato a ser testado em diferentes concentrações.

A concentração de $100 \%$ correspondeu a solução de $5 \mathrm{mg} \mathrm{mL}^{-1}$ do extrato seco no respectivo solvente. A partir da concentração inicial, foram feitas diluições obtendo-se as concentrações de 75, 50 e $25 \%$ para cada extrato testado, com quatro repetições para cada tratamento. Para o controle negativo foi usada água destilada.

Em seguida foi feita a aplicação de $10 \mathrm{~mL}$ de solução de cada um dos extratos nas placas. Após a completa evaporação do solvente, os papéis de filtro contido nas placas foram umedecidos com $10 \mathrm{~mL}$ de água destilada e colocados 25 sementes de pepino, já tratadas com hipoclorito, por placa. O desenvolvimento das plântulas ocorreu em germinador Eletrolab modelo $102 \mathrm{FC}$, a temperatura de $25 \pm 1^{\circ} \mathrm{C}$ e fotoperíodo de 12 horas. Os efeitos dos extratos sobre o comprimento da raiz principal, do hipocótilo e do número de raízes secundárias foram avaliados após seis dias de experimento.

\section{Avaliação da atividade antimicrobiana por CIM (Concentração Inibitória Mínima)}

A atividade antimicrobiana foi determinada através do teste da microdiluição (Ellof, 1998). Os extratos, diluídos em água e Tween 80 , foram testados em concentrações entre 0,031 a 2,0 $\mathrm{mg} \mathrm{mL}^{-1}$ para os microrganismos Pseudomonas aeroginosa (ATCC 13388), Escherichia coli (ATCC 11775), Rhodococcus equi (ATCC 25729), Micrococcus luteus (ATCC 4698), Staphylococcus epidermides (ATCC 12228), Salmonella choleraesuis (ATCC 10708), Enterococcus faecium (CCT 5079), Enterococcus hirae (ATCC 10541), Bacillus subtilis (ATCC 6051), Staphylococcus aureus (ATCC 6538) e Candida albicans ATCC 10231.

Os inóculos foram preparados a partir de culturas de crescimento recente (24 horas), cuja turvação foi comparada à escala McFarland $(0,5)$ e diluídos para concentração final de $10^{4}$ células $\mathrm{mL}^{-1}$. Após incubação dos microrganismos na presença dos extratos por 24 horas a $37^{\circ} \mathrm{C}, 50 \mu \mathrm{L}$ de solução $0,5 \%$ de TTC (cloreto de trifenil tetrazolium) foram adicionados e a placa re-incubada por três horas. A CIM foi definida como a menor concentração do extrato que inibia um crescimento observável. Como padrão de referência foi utilizado cloranfenicol (bactérias) ou nistatina (Candida albicans).

\section{Avaliação da capacidade antioxidante}

\section{A. Ensaio quantitativo com DPPH $(2,2-$ difenil-1-picril-hidrazila)}

Para este ensaio foi utilizado o protocolo descrito por Brand-Williams et al. (1995) e modificado por Brem et al. (2004). Diluições sucessivas dos extratos $\left(0,25\right.$ a $250 \mu \mathrm{g} \mathrm{mL}^{-1}, 100 \mu \mathrm{L}$ compartimento- $\left.{ }^{-1}\right)$ foram colocadas em placas de 96 poços, em triplicata. Em seguida, $100 \mu \mathrm{L}$ compartimento-1 de solução recém preparada de $\mathrm{DPPH}\left(0,16 \mu \mathrm{g} \mathrm{mL}^{-1} \mathrm{em}\right.$ metanol $)$ foram adicionados sobre as amostras. A leitura da absorbância foi feita a $515 \mathrm{~nm}$, em leitor de microplacas (Versa Max, Molecular Devices) a cada 5 min até completar o tempo final de $30 \mathrm{~min}$. A curva de calibração de DPPH foi preparada para conversão dos valores de absorbância em concentração. Trolox (ácido 6-hidróxi-2,5,7,8-tetrametilcromano-2-carboxílico) foi utilizado como o antioxidante de referência.

A porcentagem de DPPH livre foi calculada como \% DPPH $\mathrm{Divere}=100 \times\left([\mathrm{DPPH}]_{\text {live }} /[\mathrm{DPPH}]_{\mathrm{T} 0}\left(\mathrm{~T}_{0}\right.\right.$ concentração inicial). Com esses valores, foram construídos gráficos relacionando a porcentagem de $\mathrm{DPPH}_{\text {live }}$ com a concentração da amostra utilizandose software MS Office Excel 2003. A partir desses gráficos, calculou-se a concentração efetiva $50\left(\mathrm{CE}_{50}\right)$, definida como aquela capaz de reduzir a concentração inicial $\left(T_{0}\right)$ de DPPH em $50 \%$, através de regressão logarítmica, utilizando-se o mesmo software. O tempo necessário para se alcançar a $\mathrm{CE}_{50}\left(\mathrm{TCE}_{50}\right)$ foi obtido experimentalmente. Jiménez-Escrig et al. (2000) propuseram também uma forma de correlacionar $\mathrm{CE}_{50}$ com o $\mathrm{TCE}_{50}$, calculando-se a eficiência antiradicalar (EA) através da expressão $E A=1 /\left(C_{50} \times T_{C E}\right)$.

\section{B. Ensaio de Folin-Ciocalteau}

Utilizou-se a metodologia descrita por Prior et al. (2005) com algumas modificações. Preparouse, a partir de cada amostra, uma solução aquosa de $1,0 \mathrm{mg} \mathrm{mL}^{-1}$ e uma alíquota de $10 \mu \mathrm{L}$ dessa solução foi diluída com $600 \mu \mathrm{L}$ de água destilada. Esta solução foi então colocada em quatro compartimentos de uma placa de 96 poços (150 $\left.\mu \mathrm{L}_{\text {compartimento }}{ }^{-1}\right)$ sendo que os quatro primeiros da coluna $1(\mu \mathrm{m})$ foram preenchidos com $150 \mu \mathrm{L}$ de água (branco).

Em seguida foi adicionado a cada compartimento, o reagente de Folin-Ciocalteau (12,5 $\mu \mathrm{L})$, seguido de solução de $\mathrm{Na}_{2} \mathrm{CO}_{3}(37,5 \mu \mathrm{L}, 1 \mathrm{M})$ e 
água destilada $(50 \mu \mathrm{L})$. A placa foi incubada por duas horas a $37^{\circ} \mathrm{C}$. Todos os procedimentos acima foram realizados em triplicata. Ao final desse período, foi realizada a leitura da absorbância em $725 \mathrm{~nm}$ (Versa Max, Molecular Devices).

Foi realizada curva de calibração para ácido gálico (antioxidante de referência). A absorbância média obtida para cada amostra testada foi convertida em miligramas de ácido gálico por grama de amostra, através da equação da reta obtida para a curva do ácido gálico.

\section{Análise estatística}

Para estudo da atividade alelopática foi feito um delineamento experimental inteiramente casualizado, com quatro repetições para cada tratamento. Como os dados não apresentaram normalidade e homogeneidade, os extratos de mesma concentração foram avaliados através do teste nãoparamétrico de Kruskal-Wallis, seguido do teste de Student Newman Keuls, utilizando o programa Bioestat 5.0. Já os extratos com valores crescentes de concentração foram analisados por regressões utilizando o mesmo programa.

\section{RESULTADO E DISCUSSÃO}

$\mathrm{Na}$ análise dos valores de $\mathrm{pH}$, os extratos de $P$. venusta não mostraram diferença marcante entre estes e a água destilada (Tabela 1). Logo, este não foi fator de interferência no desenvolvimento inicial das plântulas de pepino, uma vez que extremos de pH podem mascarar o efeito alelopático (Ferreira \& Áquila, 2000).

Estudos em alelopatia têm mostrado que 0 desenvolvimento das plântulas, em geral, é mais afetado que a germinação (Ferreira \& Áquila, 2000). Por este motivo, foram analisados os efeitos dos extratos de $P$. venusta no comprimento da raiz principal, no número de raízes secundárias e no comprimento do hipocótilo de pepino, sendo os extratos orgânicos comparados entre si na mesma faixa de concentração e com o grupo controle.
TABELA 1. Valores de $\mathrm{pH}$ do controle e dos extratos de $P$. venusta.

\begin{tabular}{lc}
\hline \multicolumn{1}{c}{ Tratamento } & pH \\
\hline Controle (água destilada) & 6,01 \\
Hexano & 6,11 \\
Acetato de Etila & 5,75 \\
Metanol & 6,65 \\
\hline
\end{tabular}

Para a raiz principal, o extrato hexânico causou inibição do crescimento nas concentrações de 75 e 100\% (Tabelas 2 a 5). Já, os extratos acetato e metanol apresentaram efeito inibitório sobre o crescimento da raiz em todas as concentrações testadas $(p<0,05)$, sendo este efeito mais severo para o extrato metanólico (Tabelas 2 a 5). O comprimento do hipocótilo foi afetado apenas pelos extratos hexânico e metanólico, observando-se efeito inibitório em todas as concentrações testadas (Tabelas 2 a 5). Esses resultados corroboram os relatos de outros estudos, que apontam que o efeito causado por extratos sobre o crescimento inicial, é a redução no tamanho do eixo hipocótilo-raiz da planta-alvo (Silva \& Áquila, 2006), sendo que a raiz foi o maior contribuinte nessa inibição (Tabelas 2 a 5). Quanto às raízes secundárias foi observado que os três extratos avaliados inibiram a formação das mesmas (Tabelas 2 a 5).

Também foi analisado o efeito do aumento da concentração dos extratos sobre as plântulas de pepino, sendo cada extrato avaliado individualmente. O extrato hexânico apresentou efeitos inibitórios, dependentes da concentração, sobre o comprimento da raiz, o comprimento do hipocótilo e o número de raízes secundárias em pepino (Figura 1).

Por sua vez, o extrato acetato não inibiu o crescimento do hipocótilo, mas apresentou ação inibitória dependente da concentração, sobre a raiz principal. Já o número das raízes secundárias foi afetado de maneira muito semelhante pelas concentrações de 50, 75e 100\%, com ligeira diminuição do efeito (maior número de raízes secundárias) na

TABELA2. Efeito alelopático dos extratos de $P$. venusta, na concentração de $25 \%$, sobre o desenvolvimento inicial de pepino. Os valores representam a mediana e o desvio interquartílico ( $n=4,25$ sementes por réplica).

\begin{tabular}{lcccccc}
\hline & \multicolumn{5}{c}{ Parâmetros } \\
\cline { 2 - 7 } \multicolumn{1}{c}{ Tratamentos } & \multicolumn{2}{c}{ Hipocótilo } & \multicolumn{2}{c}{ Raiz principal } & \multicolumn{2}{c}{$\mathrm{N}^{2}$ de raízes } \\
\hline Controle & $3,30 \mathrm{a}^{*}$ & 0,50 & $11,00 \mathrm{a}$ & 3,43 & $19,00 \mathrm{a}$ & 7,25 \\
Hexano & $2,70 \mathrm{~b}$ & 0,50 & $11,28 \mathrm{a}$ & 3,03 & $22,00 \mathrm{a}$ & 9,00 \\
Acetato de Etila & $3,35 \mathrm{a}$ & 0,85 & $8,45 \mathrm{~b}$ & 1,53 & $15,57 \mathrm{~b}$ & 4,00 \\
Metanol & $2,70 \mathrm{~b}$ & 1,03 & $3,55 \mathrm{c}$ & 1,23 & $12,00 \mathrm{c}$ & 6,00 \\
\hline
\end{tabular}

* Medianas seguidas de letra igual indicam diferenças não significativas $(p>0,05)$.

Rev. Bras. PI. Med., Botucatu, v.13, n.4, p.447-455, 2011. 
TABELA3. Efeito alelopático dos extratos de $P$. venusta, na concentração de $50 \%$, sobre o desenvolvimento inicial de pepino. Os valores representam a mediana e o desvio interquartílico ( $n=4,25$ sementes por réplica).

\begin{tabular}{|c|c|c|c|c|c|c|}
\hline \multirow{3}{*}{$\frac{\text { Tratamentos }}{\text { Controle }}$} & \multicolumn{6}{|c|}{ Parâmetros } \\
\hline & \multicolumn{2}{|c|}{ Hipocótilo } & \multicolumn{2}{|c|}{ Raiz principal } & \multicolumn{2}{|c|}{ № de raízes } \\
\hline & $3,30 a^{*}$ & 0,50 & $11,00 \mathrm{a}$ & 3,43 & $19,00 \mathrm{a}$ & 7,25 \\
\hline Hexano & $2,12 b$ & 0,73 & $11,00 \mathrm{a}$ & 3,43 & $13,22 b$ & 4,25 \\
\hline Acetato de Etila & $3,90 \mathrm{a}$ & 1,33 & $6,80 \mathrm{~b}$ & 1,65 & $14,50 \mathrm{~b}$ & 4,50 \\
\hline Metanol & $2,40 \mathrm{~b}$ & 0,63 & $2,10 \mathrm{c}$ & 1,63 & $11,50 \mathrm{~b}$ & 8,00 \\
\hline
\end{tabular}

* Medianas seguidas de letra igual indicam diferenças não significativas $(p>0,05)$.

TABELA4. Efeito alelopático dos extratos de $P$. venusta, na concentração de $75 \%$, sobre o desenvolvimento inicial de pepino. Os valores representam a mediana e o desvio interquartílico ( $n=4,25$ sementes por réplica).

\begin{tabular}{lcccccc}
\hline & \multicolumn{6}{c}{ Parâmetros } \\
\cline { 2 - 7 } \multicolumn{1}{c}{ Tratamentos } & \multicolumn{2}{c}{ Hipocótilo } & \multicolumn{2}{c}{ Raiz principal } & \multicolumn{2}{c}{$^{0}$ de raízes } \\
\hline Controle & $3,30 \mathrm{a}^{*}$ & 0,50 & $11,00 \mathrm{a}$ & 3,43 & $19,00 \mathrm{a}$ & 7,25 \\
Hexano & $1,70 \mathrm{c}$ & 0,73 & $6,70 \mathrm{~b}$ & 1,53 & $8,89 \mathrm{c}$ & 3,00 \\
Acetato de Etila & $4,00 \mathrm{~b}$ & 0,70 & $5,70 \mathrm{~b}$ & 1,58 & $13,00 \mathrm{~b}$ & 3,00 \\
Metanol & $1,50 \mathrm{c}$ & 0,73 & $1,20 \mathrm{c}$ & 0,73 & $6,00 \mathrm{c}$ & 7,00 \\
\hline \multicolumn{1}{c}{${ }^{*}$ Medianas seguidas de letra igual indicam diferenças não significativas $(\mathrm{p}>0,05)}$.
\end{tabular}

TABELA 5. Efeito alelopático dos extratos de $P$. venusta, na concentração de $100 \%$, sobre o desenvolvimento inicial de pepino. Os valores representam a mediana e o desvio interquartílico ( $n=4,25$ sementes por réplica).

\begin{tabular}{lcccccc}
\hline \multirow{2}{*}{ Tratamentos } & \multicolumn{6}{c}{ Parâmetros } \\
\cline { 2 - 7 } & \multicolumn{2}{c}{ Hipocótilo } & \multicolumn{2}{c}{ Raiz principal } & \multicolumn{2}{c}{$\mathrm{N}^{2}$ de raízes } \\
\hline Controle & $3,30 \mathrm{a}$ & 0,50 & $11,00 \mathrm{a}$ & 3,43 & $19,00 \mathrm{a}$ & 7,25 \\
Hexano & $1,60 \mathrm{~b}$ & 0,83 & $5,87 \mathrm{~b}$ & 1,53 & $9,12 \mathrm{c}$ & 2,25 \\
Acetato de Etila & $3,55 \mathrm{a}$ & 1,30 & $5,50 \mathrm{~b}$ & 1,90 & $13,00 \mathrm{~b}$ & 3,25 \\
Metanol & $1,50 \mathrm{~b}$ & 1,45 & $1,50 \mathrm{c}$ & 1,45 & $6,50 \mathrm{c}$ & 10,25 \\
\hline
\end{tabular}

* Medianas seguidas de letra igual indicam diferenças não significativas $(p>0,05)$.

concentração de $25 \%$ (Figura 2). Para o extrato metanólico, as concentrações utilizadas afetaram significativamente, e de maneira dependente da concentração, o comprimento do hipocótilo e a formação de raízes secundárias em pepino. Um efeito inibitório similar foi observado no comprimento da raiz, com um máximo de inibição para a concentração de $75 \%$ e mantido para a concentração de 100\% (Figura 3).

Diante do exposto, verificou-se que a ação dos extratos orgânicos de $P$. venusta foi maior no desenvolvimento da raiz principal, a qual teve seu comprimento afetado por todos os extratos testados, dependendo da concentração utilizada. De maneira semelhante, o número de raízes secundárias também foi afetado pelos três extratos, sendo o extrato metanólico o mais ativo na inibição do crescimento e desenvolvimento deste órgão. Já o comprimento do hipocótilo foi afetado apenas pelos extratos hexânico e metanólico, indicando que os compostos presentes nas folhas de $P$. venusta, com ação sobre o desenvolvimento da parte aérea de pepino, são de baixa e de alta polaridade.

Algumas bignoniáceas como Tecoma stans (Binutu \& Lajubutu, 1994), Oroxylum indicum (Houghton et al., 1997), Newbouldia laevis (Eyong et al., 2006) Clytostoma callistegioides (Cham.) Bur. (cipó-ouro) e Jacarandra micrantha (Cham.) (Wiest et al., 2009) são conhecidas por apresentarem atividade antimicrobiana. Por causa do histórico de potencialidade microbiológica desta família, resolveuse testar esta atividade para os extratos orgânicos da folha de $P$. venusta.

Duarte et al. (2005) classificaram a atividade dos extratos como forte atividade $\left(\mathrm{MIC} \leq 0,5 \mathrm{mg} \mathrm{mL}^{-1}\right)$, 

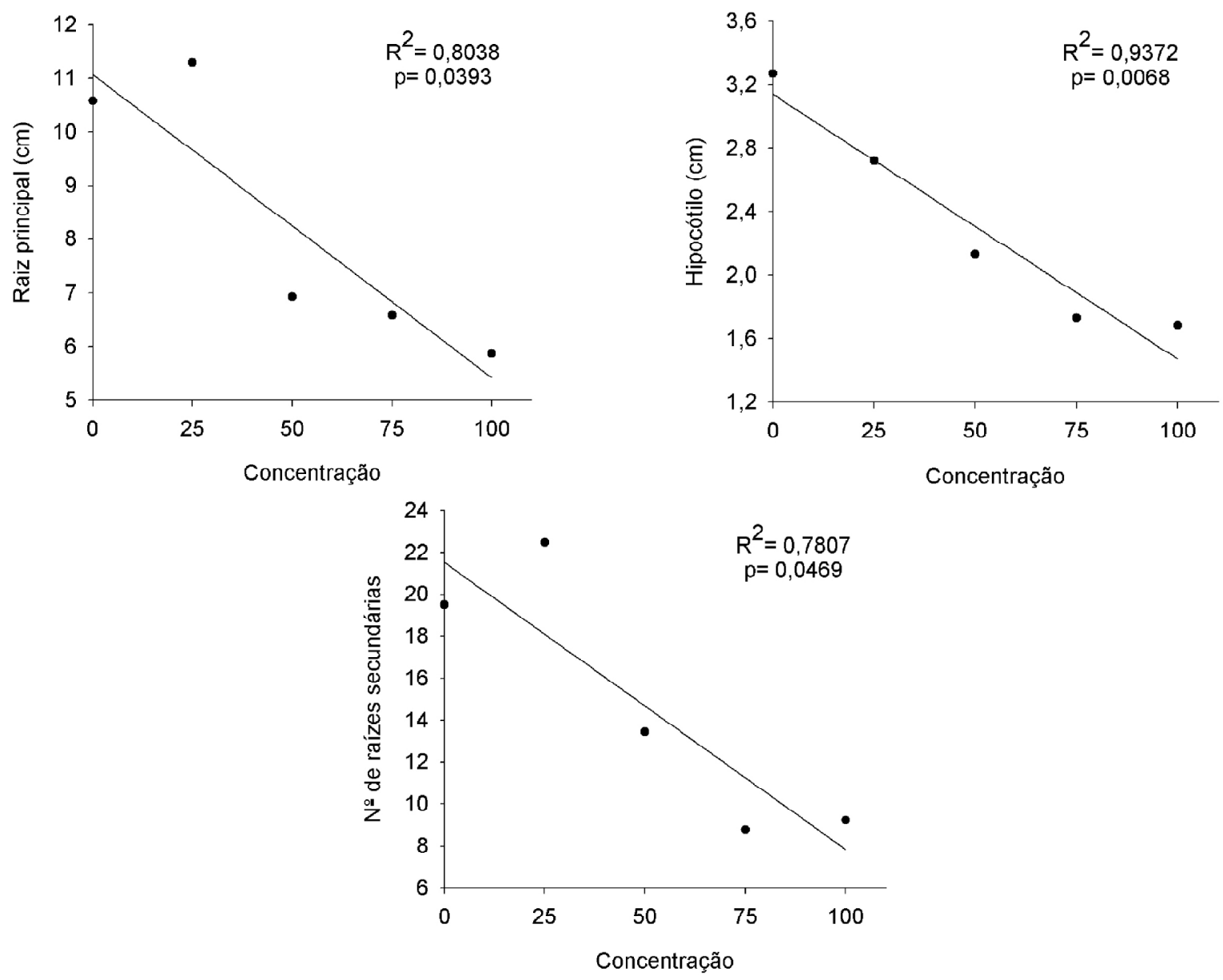

FIGURA 1. Efeitos do extrato hexano de $P$. venusta sobre o comprimento da raiz principal, comprimento do hipocótilo e número de raízes secundárias em pepino.
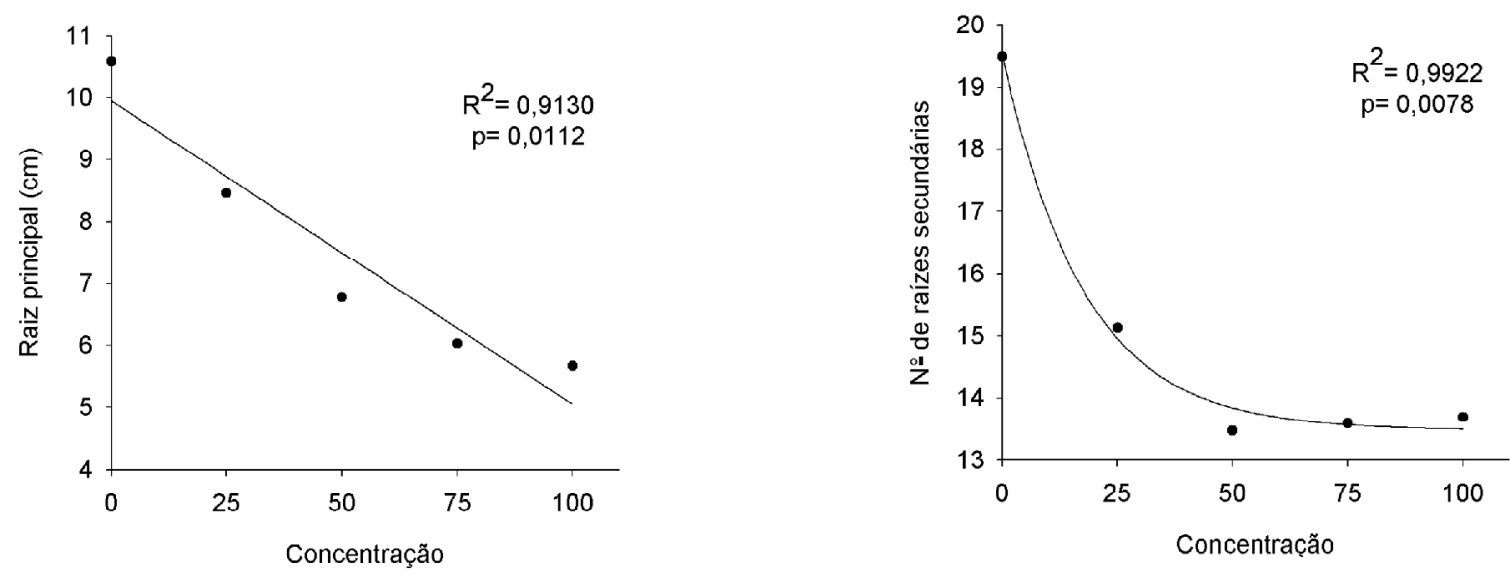

FIGURA 2. Efeitos do extrato acetato de $P$. venusta sobre o comprimento da raiz principal e o número de raízes secundárias em pepino.

moderada atividade (MIC 0,51 a 1,0 $\mathrm{mg} \mathrm{mL}^{-1}$ ) e fraca atividade (MIC $\left.\geq 1,0 \mathrm{mg} \mathrm{mL}^{-1}\right)$. Seguindo este critério, 0 extrato hexânico mostrou moderada inibição contra Staphylococcus aureus $\left(0,9 \mathrm{mg} \mathrm{mL}^{-1}\right)$ e boa inibição contra Enterococcus hirae $\left(0,5 \mathrm{mg} \mathrm{mL}^{-1}\right)$, ambas bactérias grampositivas, mas não inibiu o crescimento dos demais microrganismos usados. Embora o extrato acetato tenha apresentado apenas uma discreta inibição do crescimento $\left(1,0 \mathrm{mg} \mathrm{mL}^{-1}\right)$ para a maioria dos microrganismos, este extrato mostrou forte atividade contra a levedura Candida albicans $\left(0,3 \mathrm{mg} \mathrm{mL}^{-1}\right)$ e o extrato metanólico não se mostrou ativo para os microrganismos testados (Tabela 6). E nenhum dos extratos mostrou atividade para as bactérias gram-negativas. 

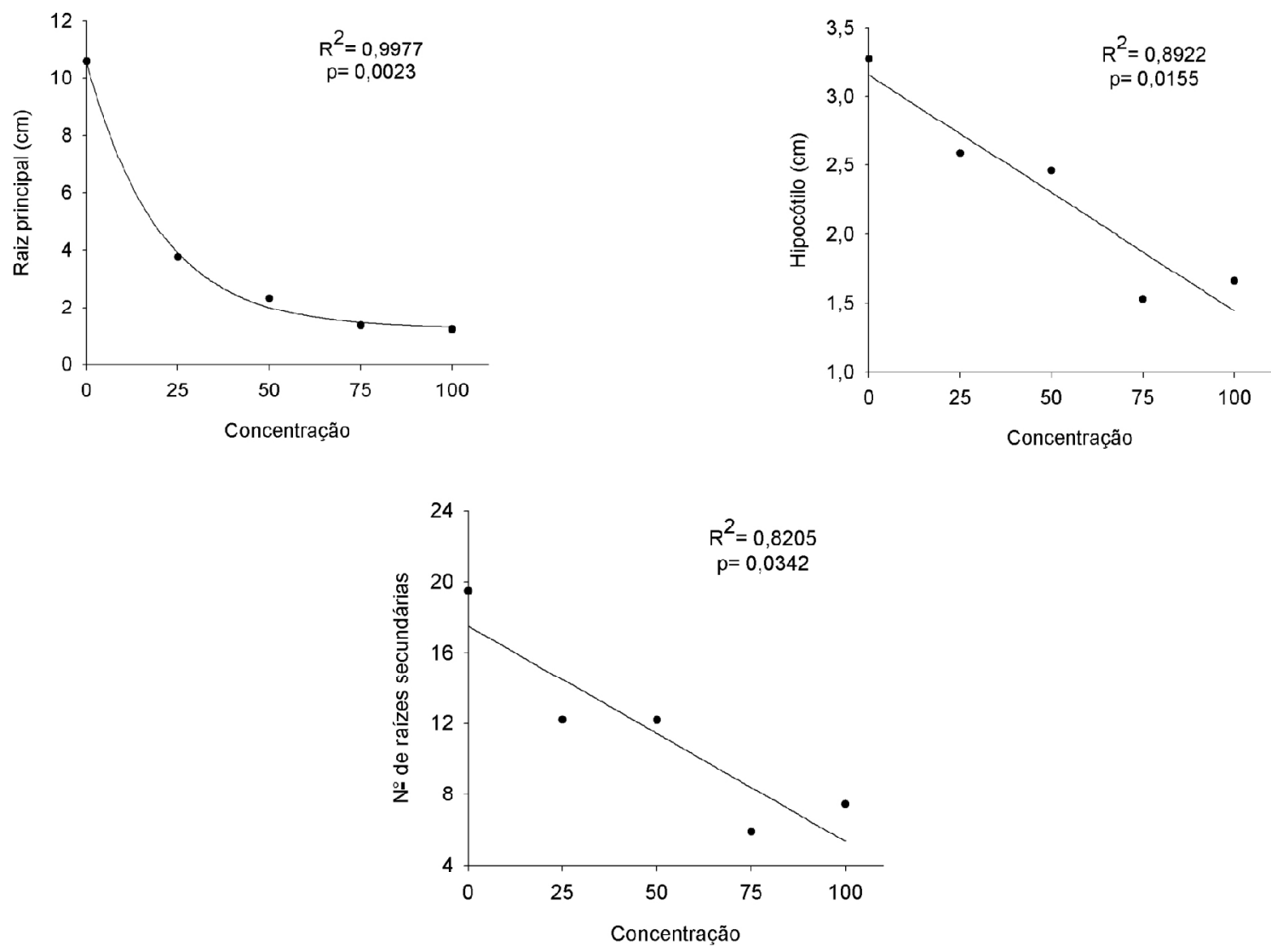

FIGURA 3. Efeitos do extrato metanol de P. venusta sobre o comprimento da raiz principal, comprimento do hipocótilo e o número de raízes secundárias em pepino.

TABELA6. Concentração inibitória mínima dos extratos das folhas de $P$. venustafrente a diferentes microrganismos.

\begin{tabular}{|c|c|c|c|}
\hline \multirow{2}{*}{ Microrganismos $^{a}$} & \multicolumn{3}{|c|}{ CIM mg mL ${ }^{-1}$} \\
\hline & EHPV & EAPV & EMPV \\
\hline \multicolumn{4}{|l|}{ Bactérias gram-positiva } \\
\hline Bacillus subtilis (ATCC 6051) & $>1,0$ & $>1,0$ & $>1,0$ \\
\hline Enterococcus faecium (CCT 5079) & $>1,0$ & $>1,0$ & $>1,0$ \\
\hline Enterococcus hirae (ATCC 10541) & 0,5 & $>1,0$ & $>1,0$ \\
\hline Micrococcus luteus (ATCC 4698) & $>1,0$ & $>1,0$ & $>1,0$ \\
\hline Rhodococcus equi (ATCC 25729) & 0,9 & $>1,0$ & $>1,0$ \\
\hline Staphylococcus aureus (ATCC 6538) & $>1,0$ & 1,0 & $>1,0$ \\
\hline Staphylococcus epidermides (ATCC 12228) & $>1,0$ & $>1,0$ & $>1,0$ \\
\hline \multicolumn{4}{|l|}{ Bactérias gram-negativa } \\
\hline Salmonella choleraesuis (ATCC 10708) & $>1,0$ & $>1,0$ & $>1,0$ \\
\hline Pseudomonas aeruginosa (ATCC 13388) & $>1,0$ & $>1,0$ & $>1,0$ \\
\hline Escherichia coli (ATCC 11715) & $>1,0$ & $>1,0$ & $>1,0$ \\
\hline \multicolumn{4}{|l|}{ Levedura $^{\mathrm{b}}$} \\
\hline Candida albicans (ATCC 10231) & $>1,0$ & 0,3 & $>1,0$ \\
\hline
\end{tabular}

a. ATCC=American Type Culture Collection, CCT=Coleção Cultura Tropical b. antibióticos padrão: cloranfenicol (bactéria), nistatina (levedura) 
Procurou-se, também, avaliar a atividade antioxidante dos extratos $P$. venusta, pois resultado antioxidante positivo poderia indicar a existência de outros tipos de atividade, como por exemplo, a bactericida e a antiinflamatória (Paula-Junior et al., 2006). A fim de verificar o teor de fenóis e a atividade antioxidante dos extratos de $P$. venusta, foram realizados os testes de Folin-Ciocalteau e o de DPPH.

O método de Folin-Ciocalteau baseia-se na transferência de um elétron, medindo assim a capacidade redutora do antioxidante em estudo. As vantagens desse método são a disponibilidade comercial dos reagentes, a absorção do grupo cromóforo em $730 \mathrm{~nm}$, o que reduz a interferência de substâncias coradas presentes na amostra, o grande número de dados disponíveis na literatura e a praticidade de implantação, uma vez que se trata de um ensaio simples, rápido, barato e robusto (Prior et al., 2005). Este ensaio é amplamente conhecido na literatura como dosagem de compostos fenólicos totais. Pelos resultados obtidos nesse teste, o extrato metanol tem maior teor de compostos fenólicos do que os extratos hexano e acetato, que por sua vez apresentaram resultados muito próximos (Tabela 7). Tendo em vista que o extrato metanol foi o mais ativo na inibição do desenvolvimento da raiz (bioensaio de alelopatia), é provável que os compostos fenólicos estejam relacionados a esta resposta, o que está de acordo com o trabalho de Ortega et al. (1996).
Outro experimento in vitro muito utilizado para verificar a capacidade de sequestrar radicais livres de extratos vegetais e/ou metabólitos é o ensaio com o radical estável 2,2-difenil-1-picril-hidrazila (DPPH). É um ensaio simples, rápido e preciso baseado na capacidade redutora do antioxidante sendo que a abstração de um átomo de hidrogênio ocorre como reação secundária (método misto) (Prior et al., 2005; Andrade et al., 2007).

Os extratos de $P$. venusta mostraram ter, no melhor dos casos, fraca atividade antioxidante, pois foram menos ativos que o Trolox. Dos três extratos, o metanólico foi o que apresentou maior eficiência antiradicalar (Tabela 7). Segundo Sánchez-Moreno (2002), o comportamento cinético de uma amostra, no ensaio de DPPH, pode ser classificado como rápido $\left(\mathrm{TCE}_{50}<5 \mathrm{~min}\right)$, intermediário $\left(\mathrm{TCE}_{50}\right.$ entre $5 \mathrm{e}$ $30 \mathrm{~min}$ ) ou lento (TCE ${ }_{50}>30 \mathrm{~min}$ ). Desta forma, o comportamento do extrato metanólico pode ser classificado como lento. Durante os experimentos foi possível observar ainda que o extrato acetato, na maior concentração testada, reduziu para $60 \%$ da concentração inicial de DPPH após 30 min de reação, sugerindo a presença de compostos com capacidade de capturar radicais livres em concentração muito menor do que aquela observada para o extrato metanol. Já o extrato hexano não apresentou capacidade de capturar radicais livres nas condições empregadas.

TABELA 7. Avaliação da atividade antioxidante dos extratos de $P$. venusta pelos ensaios do DPPH e de FolinCiocalteau.

\begin{tabular}{|c|c|c|c|c|}
\hline & \multicolumn{3}{|c|}{$\mathrm{DPPH}^{\mathrm{a}}$} & \multirow{2}{*}{$\begin{array}{c}\mathrm{FCR}^{\mathrm{a}} \\
\left(\mathrm{mg}^{\text {ácido gálico g }}\right. \\
\text { extrato }^{-1} \text { ) }\end{array}$} \\
\hline & $\mathrm{CE}_{50}{ }^{\mathbf{b}}$ & $\mathrm{TCE}_{50}{ }^{\mathbf{b}}$ & $E A^{b}$ & \\
\hline Hexano & inativo & inativo & inativo & $55,0 \pm 3,3$ \\
\hline Acetato de Etila & * & * & * & $54,7 \pm 0,7$ \\
\hline Metanol & $102,0 \pm 56,9$ & 30 & $0,00032 \pm 0,00043$ & $116,22 \pm 83,0$ \\
\hline Trolox & $1,13 \pm 0,7$ & 0,1 & $8,98 \pm 1,4$ & - \\
\hline
\end{tabular}

a. média \pm desvio padrão b. $C E_{50}$ : concentração necessária para reduzir em $50 \%$ a concentração inicial de $\mathrm{DPPH}\left(\mathrm{mg} \mathrm{mL}^{-1}\right), \mathrm{TCE}_{50}$ : tempo necessário para atingir a $C E_{50}$ (em minutos), $E A$ : eficiência antiradicalar $E A=1 /\left(C_{50}{ }^{*} T_{C E}\right)_{50}$ *decaimento de 100 a $60 \%$ da concentração do DPPH após 30 min.

\section{CONCLUSÃO}

Os resultados obtidos para $P$. venusta indicam que os extratos testados apresentam ação alelopática, interferindo principalmente no desenvolvimento da raiz principal e na formação de raízes secundárias. Por outro lado, o extrato hexano apresentou promissora atividade antimicrobiana contra Enterococcus hirae $\left(0,5 \mathrm{mg} \mathrm{mL}^{-1}\right)$ enquanto o extrato acetato foi ativo contra Candida albicans $(0,3$ $\mathrm{mg} \mathrm{mL}^{-1}$ ). Finalmente, os extratos testados não foram promissores quanto à atividade antioxidante, sendo que os melhores resultados foram obtidos para o extrato metanólico. Sendo assim, as atividades mais promissoras para os extratos orgânicos testados da $P$. venusta são a antimicrobiana e a alelopática. 


\section{REFERÊNCIA}

ALVES, M.C.S. et al. Alelopatia de extratos voláteis na germinação de sementes e no comprimento da raiz de alface. Pesquisa Agropecuária Brasileira, v.39, p.10836, 2004.

ANDRADE, C.A. et al. Determinação do conteúdo fenólico e avaliação da atividade antioxidante de Acacia podalyriifolia A. Cunn ex. Don Leguminosae-Mimosoidae. Revista Brasileira Farmacognosia, v.17, p.231-5, 2007. BAGCHI, G.D.; JAIN, D.C.; KUMAR, S. Arteether: a potent plant growth inhibitor from Artemisia annua. Phytochemistry, v.45, p.1131-3, 1997.

BINUTU, O.A.; LAJUBUTU, B.A. Antimicrobial potentials of some plant species of the Bignoniaceae family. African Journal of Medicine and Medical Sciences, v.23, p.26973, 1994.

BLATT, C.T.T.; SANTOS, M.D.; SALATINO, A. Flavonoids of Bignoniaceae from the "cerrado" and their possible taxonomic significance. Plant Systematics and Evolution, v.210, p.289-92, 1998.

BRAND-WILLIAMS, W.; CUVELIER, M.E.; BERSET, C. Use of a free radical method to evaluated antioxidant activity. Lebensm-Wiss u-Technol, v.28, p.25-30, 1995.

BREM, B. et al. Antioxidant dehydrotocopherols as a new chemical character of Stemona species. Phytochemistry, v.65, p.2719-29, 2004.

CARMO, F.M.S.; BORGES, E.E.L.;TAKAKI, M. Alelopatia de extratos aquosos de canela-sassafrás (Ocotea odorifera (Vell.) Rohwer Acta Botanica Brasílica, v.21, p.697-705, 2007. DEGASPARI, C.H.; WASZCZYNSKYJ, N. Antioxidants properties of phenolic compounds. Visão Acadêmica, v.5, p.33-40, 2004.

DUARTE, M.C.T. et al. Anti-Candida activity of Brazilian medicinal plants. Journal of Ethnopharmacology, v.97, p.305-11, 2005.

DUBEY, R.C.; MISRA, K. Chemical components of Pyrostegia venusta flowers. Journal Indian Chemical Society, v.53, p.378-81, 1976.

ELLOF, J.N. A sensitive and quick microplate method to determine the minimal inhibitory concentration of plant extracts for bacteria. Planta Medica, v.64, p.711-3, 1998. EYONG, K.O. et al. Newbouldiaquinone A: A naphtoquinone- antraquinone ether coupled pigment, as a potential antimicrobial and antimalarial agent from Newbouldia laevis. Phytochemistry, v.67, p.605-9, 2006. FERREIRA, A.G.; ÁQUILA, M.E.A. Alelopatia: uma área emergente da ecofisiologia. Revista Brasileira de Fisiologia Vegetal, v.12, p.175-204, 2000.

FERREIRA, D.T. et al. Constituintes químicos das raízes de Pyrostegia venusta e considerações sobre a sua importância medicinal. Quimica Nova, v. 23, p.42-6, 2000. HOUGHTON, P.J.; MAT ALI, R.; AZIZOL, M. Antimicrobial activity of extracts of some Bignoniaceae from Malaysia. Pharmaceutical and Pharmacological Letters, v.7, p.968, 1997.

JIMÉNEZ-ESCRIG, A. et al. Evaluation of free radical scavenging of dietary carotenoids by the stable radical 2,2-diphenyl-1-picrylhydrazyl. Journal of the Science of Food and Agriculture, v.80, p.1686-90, 2000.

MAGALHÃES, E.A. et al. Avaliação do potencial genotóxico do extrato bruto de Pyrostegia venusta (Ker Gawl.) Miers, Bignoniaceae, em medula óssea de camundongos Revista Brasileira Farmacognosia, v.20, p.65-9, 2010. MARONI, B.C.; DI STASI, C.; MACHADO, S.R. Plantas medicinais do cerrado de Botucatu: guia ilustrado. São Paulo: Editora UNESP, 2006. 194p.

ORTEGA, M.C. et al. Behaviour of different horticultural species in phytotoxicity bioassays of bark substrates. Scientia Horticulturae, v.66, p.125-32, 1996.

OSTROSKY, E.A. et al. Métodos para avaliação da atividade antimicrobiana e determinação da concentração mínima inibitória (CMI) de plantas medicinais. Revista Brasileira Farmacognosia, v.18, p.301-7, 2008.

PAULA-JUNIOR, W. et al. Leishmanicidal, antibacterial and antioxidant activities of Caryocar brasilience Cambess leaves hydroethanolic extract. Revista Brasileira Farmacognosia, v.16, p.625-30, 2006.

PRIOR R.L.; WU, X.; SCHAICH, K. Standardized methods for the determination and antioxidant capacity and phenolics in food and dietary supplements. Journal of Agricultural and Food Chemistry, v.53, p.4290-302, 2005. SANCHEZ-MORENO, C. Methods used to evaluate the free radical scavenging activity in food and biological systems. Food Science Technology International, v.8, p.121-37, 2002.

SANTOS, M.D.; BLATT, C.T.T. Teor de flavonóides e fenóis totais em folhas de Pyrostegia venusta Miers. de mata e de cerrado. Revista Brasileira de Botânica, v.21, p.13540, 1998.

SATYAVATHI, M. et al. A note on the phytochemical constituents of some Bignoniaceae. Current Science India, v.53, p.711-2, 1984.

SILVA, F.M.; AQUILA, M.E.A. Contribuição ao estudo do potencial alelopático de espécies nativas. Revista Árvore, v.30, p.547-55, 2006.

SOUSA, C.M.M. et al. Fenóis totais e atividade antioxidante de cinco plantas medicinais. Química Nova, v.30, p.3515, 2007.

VELOSO, C.C. et al. Pyrostegia venusta attenuate the sickness behavior induced by lipoposaccharide in mice. Journal of Ethnopharmacology, v.132, p.335-8, 2010.

WIEST, J.M. et al. Atividade anti-estafilócica em extratos de plantas com indicativo medicinal ou condimentar. Revista Brasileira de Plantas Medicinais, v.11, n.2, p.20915, 2009. 